\title{
Estudo da experiência de uma Comunidade de Aprendizagem docente no Portal da Amazônia
}

\author{
Study of the experience of a Teacher Learning Community in the Amazon Portal
}

\author{
Maria Candida Müller ${ }^{1}$ \\ Dione Lucchesi de Carvalho ${ }^{2}$
}

\begin{abstract}
Resumo
Baseado nos dados produzidos pelas reuniões do grupo de estudo e trabalho pedagógico do Projeto de Pesquisa GETEMAT $^{3}$, ocorridas na cidade de Vilhena - RO, buscou-se caracterizá-lo como uma comunidade de aprendizagem do professor e entender o tipo de conhecimento que foi construído pelo grupo, utilizando o referencial teórico desenvolvido por Cochran-Smith e Lytle, especialmente nos trabalhos de 1993, 1999 e 2009. Os dados possibilitaram que se analisasse o grupo de acordo com as características-chave de uma comunidade de aprendizagem apresentadas pelas autoras, bem como o tipo de conhecimento gerado pelo grupo. Os indícios encontrados no material produzido pelos participantes permitem afirmar que o grupo criou um espaço de aprendizagem para os docentes, constituindo-se efetivamente em uma comunidade de aprendizagem do professor, que produziu especialmente um conhecimento para a prática docente.
\end{abstract}

Palavras-chave: Educação Matemática; Comunidades de Aprendizagem do Professor; Formação do Professor; Anos Iniciais.

\begin{abstract}
Based on the data produced by the meetings of the study group of the GETEMAT Research Project, that occurred in the city of Vilhena - RO, the aim was to characterize it as a community of teacher learning and to understand the type of knowledge which was constructed by the group, using the theoretical framework developed by Cochran-Smith and Lytle, especially in the works of 1993, 1999 and 2009. The data allowed analyzing the group according to the key characteristics of a learning community presented by the authors, as well as the understanding of the type of knowledge generated by the group. The clues found in the material produced by the participants allow us to affirm that the group created a space for learning for teachers, effectively becoming a teacher-learning community that produced especially knowledge for teaching practice.
\end{abstract}

Keywords: Mathematics Education; Teacher Learning Communities; Teacher Education.

\section{Submetido em: 01/08/2017 - Aceito em: 09/03/2018 - Publicado em: 13/06/2018}

${ }^{1}$ Doutora em Educação pela Universidade Estadual de Campinas. Professora da Universidade Federal de Rondônia, Brasil. Email: maria.candida@unir.br

${ }^{2}$ Doutora em Educação pela Universidade Estadual de Campinas. Professora da Universidade Estadual de Campinas, Brasil. Email: dione_paulo@uol.com.br

3 O Projeto GETEMAT - Grupo de Estudo e Trabalho Pedagógico de Ensino de Matemática: Formação Continuada de Professores dos Anos Iniciais Para o Ensino de Matemática foi financiado pelo CNPq, através do Edital nº55/2008 - CT Amazônia. 


\section{Para iniciar}

Estudiosos na área de formação de professores (por exemplo, Carvalho \& Pamplona, 2009; Fiorentini, 2013; Fiorentini \& Nacarato, 2010) têm discutido a importância da criação de comunidades de professores como uma forma de romper com o isolamento característico da profissão docente. Textos produzidos por essas comunidades (Carvalho \& Conti, 2009; Fiorentini \& Cristovão, 2007; Fiorentini \& Espinosa, 2003) demonstram que a participação do professor e de futuros professores em comunidades de aprendizagem contribui tanto para o processo de formação dita inicial quanto para a formação permanente ou continuada do professor.

Considera-se como fundamental caracterizar essas comunidades como um local de aprendizagem compromissada com a transformação da prática docente, pois não se constituem apenas em um espaço de queixas sobre as dificuldades encontradas nas escolas, mas compõem um espaço de estudo, reflexão, troca de experiências e construção em conjunto do saber docente, numa perspectiva de investigação.

O objetivo primeiro deste artigo foi, a partir dos dados produzidos pelo grupo de professores que participaram do projeto de pesquisa GETEMAT - Grupo de Estudo e Trabalho Pedagógico de Ensino de Matemática (Müller, 2010, 2011), caracterizá-lo como uma comunidade de aprendizagem do professor, de acordo com o referencial teórico oferecido pelos trabalhos de Cochran-Smith e Lytle. Utilizaram-se conceitos e característicaschave relativos a comunidades de aprendizagem de professores trazidos por Cochran-Smith e Lytle (1993, 2002, 2009), para revisitar os dados produzidos pelo grupo entre os anos de 2009 e 2011.

Além disso, buscou-se compreender o tipo de conhecimento produzido pelo grupo, utilizando novamente os construtos teóricos de Cochran-Smith e Lytle (1999), que caracterizam o conhecimento e aprendizagem do professor nas concepções: conhecimento para a prática, conhecimento na prática e conhecimento da prática docente.

Boa parte das reflexões apresentadas neste artigo foi elaborada durante o estágio pósdoutoral $^{4}$ da primeira autora do artigo, realizado em 2012, tendo como sua interlocutora a segunda, cujo objetivo era analisar os dados do Projeto GETEMAT a partir do referencial teórico relacionado às comunidades de aprendizagem e investigação do professor.

Comunidades de aprendizagem do professor, de acordo com o verbete elaborado por Cochran-Smith e Lytle (2002) ${ }^{5}$ para a Encyclopedia of Education (Guthrie, 2002) é um termo utilizado para se referir a projetos, programas cooperativos e colaborativos de futuros professores, professores com experiência, em parceria com professores da universidade, que apoiam a educação continuada dos participantes do grupo.

\footnotetext{
${ }^{4}$ Realizado junto ao Programa de Pós-Doutorado da Faculdade de Educação da Universidade Estadual de Campinas, na Área de Concentração: Ensino e Práticas Culturais.

${ }^{5}$ As traduções dos textos de Cochran-Smith e Lytle de 1993 e 2002 são nossas.
} 


\section{Em termos conceituais, as autoras apresentam a seguinte definição de comunidades de aprendizagem do professor:}

Conceitualmente, comunidade de aprendizagem do professor se refere a um espaço intelectual tanto quanto designa um grupo particular de pessoas e algumas vezes um espaço físico. Neste sentido, comunidades são configurações intelectuais, sociais e organizacionais que apoiam o crescimento profissional contínuo dos professores, possibilitando oportunidades para os docentes pensarem, conversarem, lerem e escreverem sobre seu trabalho diário, incluindo os seus contextos sociais, culturais e políticos de forma planejada e intencional. (Cochran-Smith \& Lytle, 2002, pp. 2462$2463)^{6}$

Como as próprias autoras afirmam, o conceito de comunidades de aprendizagem do professor tem uma variação ampla; no entanto, essas comunidades têm características que possibilitam identificá-las e, a partir das pesquisas feitas com vários grupos de professores, Cochran-Smith e Lytle (1993) estabeleceram eixos para compreensão das comunidades de aprendizagem. Esses eixos, que são características-chave das comunidades de aprendizagem, estão baseados nos seguintes aspectos: organização do tempo; utilização das conversas e discussões; construção dos textos e seleção de bibliografias de estudo; e problematização e elaboração de atividades, para serem desenvolvidas em sala de aula, que caracterizam os propósitos compartilhados pelo grupo com relação ao processo de ensinar e aprender (Cochran-Smith \& Lytle, 1993, 2002).

Esses foram os eixos utilizados neste estudo para obter indícios que permitissem a caracterização do grupo GETEMAT como uma comunidade de aprendizagem e, com isso, corroborar o que diz a literatura sobre a importância da produção de conhecimento compartilhado entre a universidade e a escola em grupos que integram docentes de diferentes níveis de ensino.

Com relação à análise do conhecimento produzido pelo grupo, utilizou-se o trabalho de Cochran-Smith e Lytle (1999), que distinguem três diferentes concepções de produção e aprendizagem de conhecimentos docentes em relação à prática de ensinar e aprender: conhecimento para a prática; conhecimento na prática; conhecimento da prática.

Cada uma dessas concepções trata a questão do conhecimento e da aprendizagem do professor de uma forma específica. O conhecimento para a prática enfatiza a produção dos pesquisadores acadêmicos e as teorias para uso do professor, com o objetivo de melhorar a prática. $\mathrm{O}$ conhecimento na prática tem como foco principal o conhecimento gerado pelos professores competentes ou experts para produzir novos saberes sobre a forma de ensinar. $\mathrm{O}$ conhecimento da prática considera que não há a separação entre o conhecimento formal e a

\footnotetext{
${ }^{6}$ Conceptually, teacher learning community refers to an intellectual space as much as it designates a particular group of people and sometimes, a physical location. In this sense, communities are the intellectual, social, and organizational configurations that support teachers' ongoing professional growth by providing opportunities for teachers to think, talk, read and write about their daily work, including its larger social, cultural, and political contexts in planned and intentional ways.
} 
prática profissional, e é produzido quando os professores tratam suas salas de aula e a escola como lugares para investigação intencional, ao mesmo tempo em que tratam o conhecimento e a teoria produzidos por outros como materiais geradores de questionamentos e interpretações, possibilitando a construção de um conhecimento de dentro da escola que poderá influenciar o conhecimento de fora, especialmente os trabalhos acadêmicos da área de educação.

No período destacado, foram realizadas 75 reuniões, com a participação de um total de 34 professores de educação básica, 4 estudantes de graduação e 2 professores da universidade. As informações geradas pelo grupo nesse período encontram-se registradas nos seguintes documentos: registros individuais da reunião, produzidos pelos professores de educação básica, os quais se denominaram de memoriais da reunião - breves relatos sobre as discussões ocorridas naquele encontro. Optou-se por esse tipo de registro devido à dificuldade dos professores da educação básica em relação ao ato de escrever, seja sobre suas atividades didáticas ou sobre suas reflexões pessoais. Além disso, a elaboração era voluntária, assim como a identificação do seu autor; diários de campo dos encontros, elaborados pelos estudantes de iniciação científica; relatórios de iniciação científica e trabalhos de conclusão de curso escritos pelos alunos do curso de Pedagogia; comunicações científicas em forma de artigos apresentados em eventos da área, tanto pelo pesquisador quanto por alunos e alunas de iniciação científica. Dentre os docentes da educação básica apenas um trabalho, nesse período, foi apresentado em eventos de Educação (Campos \& Müller, 2009).

Os documentos principais para revisitar a trajetória de constituição do grupo, buscando sua caracterização como comunidade de aprendizagem e o tipo de conhecimento produzido são os memoriais da reunião, os diários de campo e os relatos individuais de integrantes do grupo.

\section{O Grupo GETEMAT}

O grupo de estudo, também denominado GETEMAT, foi constituído ao longo do desenvolvimento do projeto de pesquisa, e dele participaram professores da educação básica do município de Vilhena (RO) que atuavam nos Anos Iniciais do Ensino Fundamental, professores da universidade e alunos do curso de Pedagogia da Universidade Federal de Rondônia, Campus de Vilhena. A cidade de Vilhena situa-se no sul do estado de Rondônia e é denominada de Portal da Amazônia, pois é o acesso terrestre para os estados de Rondônia, Acre e Amazonas.

O projeto que gerou o grupo foi concebido com a perspectiva de uma pesquisa-ação, pois buscava envolver os participantes como sujeitos ativos, capazes de transformar suas práticas, e com isso priorizou a criação de um espaço coletivo de formação a partir das reuniões do grupo de estudo e trabalho pedagógico que ocorreram tanto na universidade quanto em uma das escolas envolvidas no projeto. E, por meio de discussões sobre problemas relacionados ao aprender e ensinar matemática apresentados pelos participantes, buscou-se "ajudar o grupo a problematizá-lo[s], ou seja, situá-lo[s] em um contexto teórico mais amplo 
e assim possibilitar a ampliação da consciência dos envolvidos, com vistas a planejar as formas de transformação das ações dos sujeitos e das práticas institucionais" (Pimenta, 2005, p. 523).

O objetivo principal do grupo GETEMAT era discutir as dificuldades encontradas pelos professores dos anos iniciais para desenvolver os conteúdos de matemática com os seus alunos. A proposta principal para as reuniões era a de elaborar uma pauta de discussão em conjunto, gerada pelas demandas dos professores da educação básica.

À medida que o grupo foi se constituindo, a dinâmica dos encontros pôde ser caracterizada como uma reflexão sobre a prática docente dos participantes, a partir da discussão de textos sobre formação ou relacionados ao currículo dos anos iniciais. No diário de campo das reuniões, encontram-se os registros dos temas sugeridos pelos docentes: algoritmo da divisão, sistemas de medida, frações, resolução de problemas, sistema de numeração, entre outros. Apesar de serem temas específicos vinculados aos conteúdos matemáticos, foi a partir deles que se discutiram temas mais amplos relacionados à formação do professor, como: dificuldades ao ensinar conteúdos que não conhecem; uso de recursos como calculadora nas aulas de matemática; problematização dos conteúdos; uso de materiais manipuláveis - ábaco, material dourado, escala/barras de Cuisenaire, tangram.

Os professores dos anos iniciais que participaram do grupo GETEMAT tinham em comum o fato de serem docentes da rede municipal de Vilhena (RO), atuando nos anos iniciais das escolas urbanas do município, e estavam sujeitos às determinações desse sistema de ensino, como horário, planejamento de atividades, etc. Embora o grupo tivesse reuniões em dois períodos para contemplar o maior número possível de professores, havia um eixo comum de discussão: as dificuldades encontradas pelos docentes para desenvolver os conteúdos matemáticos - o que possibilita que se considerem esses encontros como sendo de uma mesma comunidade. Além disso, nos encontros se utilizavam os mesmos textos ${ }^{7}$ para fundamentar as discussões.

Esse grupo continuou até 2015, quando dificuldades relacionadas ao atendimento das expectativas das professoras em diferentes momentos da profissão, o tamanho do grupo, a entrada e a saída dos membros contribuíram significativamente para seu término em dezembro daquele ano.

Na seção seguinte relacionam-se as ideias de comunidade de aprendizagem do professor e suas características com os dados que foram construídos entre 2009 e 2011 pelo GETEMAT e caracteriza-se o conhecimento produzido pelo grupo.

\footnotetext{
${ }^{7}$ Araújo (2003), Curi (2005), Fiorentini e Gimenes (2004), Fiorentini e Miorim (1990), Lopes (2003), Moura (2000); Moura, Araújo, Moretti, Panossian e Ribeiro (2010), Muniz (2009), Nacarato (2005), Nacarato, Mengali e Passos (2009b), Panizza (2006), Penteado (2008), Skovsmose (2000), Toledo e Toledo (1997).
} 


\section{Análise da experiência do GETEMAT}

O GETEMAT propôs a criação de um espaço de formação que não apenas visava ao desenvolvimento de uma proposta de formação de professores, mas também propunha uma mudança na prática docente. Infelizmente, não foi possível coletar dados que indicassem essa mudança da prática, mas eles com certeza evidenciam reflexões importantes feitas no grupo, que demonstram um movimento de aprendizagem dos seus integrantes sobre o processo de ensinar e aprender.

Em uma das reuniões, ao se discutir a utilização de projetos no ensino, uma professora fez o seguinte comentário que exemplifica esse compromisso com uma aprendizagem que busca a transformação da prática:

No curso (GETEMAT) estou tendo oportunidade de pensar em projeto de uma forma diferente, mais concreta, que torna possível a aprendizagem. A proposta de se colocar em sala de aula como pesquisador, pensando num problema, nos objetivos, na metodologia de busca de dados e depois analisar estes dados coletados é uma nova maneira de se pensar a docência. Pensar a docência sob esta perspectiva pode servir de ajuda para enfrentar discursos prontos sobre o que ensinar, normalmente produzidos por pessoas que nunca estiveram em uma sala de aula, mas que julgam ter encontrado a solução para as mazelas da educação. Se me coloco como pesquisadora da minha própria prática, terei chances de verificar se aquilo que falam de fato se aplica com resultados positivos. Talvez assim possamos caminhar na direção da superação do discurso corrente que atribui à própria criança a culpa pela não aprendizagem ou ao professor por não ter feito como lhe mandaram. (Professora Anônima, Memorial, 2010)

Ao revisitar os dados produzidos pelo grupo GETEMAT, buscou-se destacar quais aspectos relacionados aos eixos apontados por Cochran-Smith e Lytle (1993, 2002) poderiam auxiliar a entender o movimento de constituição do grupo como uma comunidade de aprendizagem.

É importante observar que não se busca enquadrar a produção do grupo num arcabouço teórico já existente, mas utilizá-la para compreender as diferentes etapas que foram vivenciadas pelo grupo no período em estudo. Entende-se que a produção de um grupo é única e peculiar, e pode produzir outras categorias para sua compreensão, além daquelas oferecidas pela teoria.

O tempo é um dos fatores críticos na formação e na manutenção das comunidades de aprendizagem do professor. Quando se reúnem em grupo para refletir sobre sua prática, os professores necessitam de um tempo que lhes permita adquirir confiança para compartilhar suas experiências, angústias e desafios. A confiança é construída no processo de constituição do grupo e, à medida que o tempo passa, os participantes sentem-se seguros para tratar de questões delicadas da vida profissional. A longevidade de um grupo permite aos seus integrantes desenvolver estudos sistemáticos e espontâneos sobre sua prática de uma forma natural e confiante. 
Entretanto, o período em que foram realizados os encontros do GETEMAT não foi suficiente para construir um ambiente de confiança e cumplicidade no grupo. Em conversas informais entre a coordenadora do projeto e algumas integrantes do grupo observaram-se indícios de relações de poder entre as professoras dos Anos Iniciais, construídas fora do grupo, o que com frequência inviabilizou sua participação efetiva nas discussões. Algumas se sentiam intimidadas por seus pares, especialmente quando eram de uma mesma escola, e não se permitiam, muitas vezes, expor suas ideias e práticas, por considerá-las menores em relação às ideias e aos relatos de experiências das outras colegas.

Além do tempo para desenvolver uma relação de confiança entre seus participantes, há a questão do tempo do professor para se reunir, planejar, estudar, ou seja, o professor precisa ter o controle do seu próprio tempo. A professora que queria participar do grupo GETEMAT precisava conciliar suas atividades docentes (tempo de sala de aula, de estudo e planejamento) com o horário de sua participação nas reuniões. Apenas no ano de 2011, quando as reuniões passaram a ocorrer no espaço físico de uma das escolas, é que as professoras puderam utilizar, por alguns meses, seu horário de planejamento e estudo para participar do grupo.

A construção conjunta do conhecimento em uma comunidade de professores, segundo Cochran-Smith e Lytle (1993) ocorre através da conversa e discussão que acontecem durante os encontros, pois são formas particulares de descrever, discutir e debater o ensino. É através das conversas, da discussão que ocorre durante as reuniões, que o grupo expõe seu conhecimento tácito, questiona hipóteses da prática, gera conhecimento que permite buscar alternativas ao trabalho que seus integrantes desenvolvem.

As autoras apresentam a ideia de "pequenas conversas" (Cochran-Smith \& Lytle 1993, p. 94), nas quais os(as) docentes trocam experiências, compartilham angústias e dúvidas, buscam conselhos, comentam seu dia a dia de uma forma mais espontânea, em complemento às "grandes conversas"9 (Cochran-Smith \& Lytle 1993, p. 94), que têm um propósito mais intencional, com o tema escolhido pelo grupo. As "pequenas conversas" têm uma função importantíssima, pois criam e sustentam as relações interpessoais, imprescindíveis para um projeto mais ambicioso de construção conjunta de conhecimento.

O material produzido durante as reuniões do GETEMAT demonstra o desenvolvimento das "pequenas conversas" no grupo. Nos registros do diário de campo dos encontros há relatos sobre essas conversas, especialmente tratando das angústias com relação ao trabalho em sala de aula, dúvidas sobre a forma de trabalhar diversos conceitos matemáticos, além de questões sobre o dia a dia da escola, como reuniões de pais, projetos com os alunos, encontros pedagógicos promovidos pela Secretaria Municipal de Educação, entre outros temas.

\footnotetext{
8 "small talk"

9 "big talk"
} 
Duas professoras estavam conversando sobre o fato dos professores dos anos iniciais do município de Vilhena não dominarem os conteúdos de matemática. De acordo com elas, alunos do terceiro e quarto anos não conhecem o sistema de numeração e quando solicitados a lerem o número da página do livro, não conseguem. Comentaram que as crianças não conseguem resolver um problema, pois não conseguem ler. Na conversa falam que o professor tem que se preocupar em como vai entregar seus alunos para o próximo professor. Observaram que os professores têm que se reunirem para discutir e refletir sobre suas ações pedagógicas e não ficarem se defendendo ou procurando justificativas para as defasagens. (Diário de Campo, 9 de março de 2010)

No registro de um memorial também uma dessas conversas entre as professoras está relatada:

Estava hoje comentando com uma colega do curso que, se tivéssemos acesso a materiais concretos para exploração, não teríamos tanta dificuldade na compreensão da matemática, quando ainda estudávamos. Percebi também que algumas colegas não compreendem esse processo de dezena e unidade, mas sentem vergonha de perguntar. Acho que deveríamos fazer mais atividades em grupo para expor aos colegas, assim as dúvidas não ficariam escondidas, mas de uma forma ou de outra precisariam ser expostas. Assim, aquilo que um professor não explica na sala por medo de errar, passaria a ser um conteúdo fácil e acessível aos alunos. (Professora Anônima, Memorial, 2009)

Com relação às conversas que ocorriam durante o encontro, uma professora fez o seguinte registro, que exemplifica as discussões realizadas no grupo:

Acho interessante a maneira como a formadora faz questionamentos acerca da prática, bem com as hipóteses que levanta entre as professoras e as acadêmicas sobre a utilização do material concreto ao mesmo tempo em que relata seu surgimento na história. A partir desta problematização, o estudo dos textos e a prática se tornam mais significativas. (Professora Anônima, Memorial, 2010)

$\mathrm{Na}$ dinâmica das reuniões havia sempre a proposição de estudo de textos para subsidiar as reflexões e as discussões sobre as diversas temáticas. Geralmente, o posicionamento das professoras foi mais de concordância com os autores estudados do que de questionamentos e reflexões a partir da prática. No entanto, podem-se encontrar registros sobre as reflexões sobre a prática, provocadas pela teoria:

Normalmente não costumo participar das discussões que são realizadas nos cursos, mas hoje me senti à vontade para fazê-lo. Talvez pelo fato de sermos em poucas pessoas, isso tenha feito com que me sentisse segura para falar. Percebi que minhas colegas também possuem dificuldades para ensinar determinado conteúdo e isso de certa forma traz um alívio por pensar que não apenas eu estou precisando de ajuda. Gostei do artigo ${ }^{10}$ que lemos. É gratificante como professora saber que alguém se preocupa com minha formação continuada. (professora ECLP, Memorial 2009)

A construção do conhecimento em parceria, através das conversas, é um processo público e coletivo. As conversas que possibilitam a discussão e a problematização da prática docente permitem aos integrantes do grupo se conhecer mutuamente e construir suas ideias

\footnotetext{
${ }^{10}$ Nacarato, Mengali e Passos (2009a).
} 
de uma maneira que seria impossível de acontecer solitariamente ou individualmente. Professores iniciantes e os mais experientes têm nas conversas uma oportunidade de articular e depois questionar sua prática e seus pressupostos sobre ela, tornando mais clara e explícita a forma como entendem o processo de ensino e aprendizagem (Cochran-Smith \& Lytle, 1993).

O terceiro eixo destacado por Cochran-Smith e Lytle (1993) diz respeito ao papel dos textos na formação e na manutenção do grupo. Os diferentes tipos de textos destacados pelas autoras referem-se tanto ao material produzido pelos próprios docentes como forma de registro de sua prática, diários pessoais de aprendizagem, material gerado por seus alunos, quanto às pesquisas em ensino e aprendizagem, aos estudos realizados por outros professores e, em especial, à seleção de obras do campo teórico, que servem de perspectiva de análise para diferentes trabalhos.

Em suma, além dos textos teóricos escolhidos pelo grupo para embasar suas reflexões, demonstrando seu engajamento com diferentes perspectivas, o material que o grupo cria ao longo de sua existência é fundamental para que o docente se sinta produtor de conhecimento. A participação em eventos da área e a publicação dos resultados é, segundo as autoras, uma forma de desafiar o status quo, pois demonstra a possibilidade de o professor gerar um conhecimento sobre sua prática, diferente daquele produzido pelo especialista, porém tão importante quanto esse.

O GETEMAT teve como principal produção escrita dos docentes o memorial da reunião. Através dos memoriais foi possível revisitar as reflexões sobre o processo de aprendizagem das participantes do grupo. Por exemplo:

Hoje, dia 29/10/09, no nosso $6^{\circ}$ encontro eu me coloquei no lugar do aluno e aprendi de uma forma que jamais achei que podia aprender, ou seja, quando aprendi no meu tempo, respeitava uma regra, com esse projeto (GETEMAT) sabemos o porquê das regras. Posso confirmar que estou reaprendendo o que eu achava que sabia, se depender de mim, meus alunos vão além. (Memorial Anônimo, 2009)

Além do memorial, no final dos encontros de 2011, foi solicitado às professoras de Educação Básica e às alunas que participaram do grupo que fizessem um relato escrito sobre a experiência de participação no grupo. Uma professora fez o seguinte registro sobre o projeto e as mudanças que aconteceram na sua vida tanto profissional quanto pessoal:

Os dois anos e meio de GETEMAT me proporcionaram não somente um crescimento profissional, mas me fizeram crescer como pessoa. Ao admitir minhas limitações, fraquezas, traumas e frustrações foi certamente expor minha nudez. Admitir que não sabia ou dominava certos conteúdos foi tão significativo para mim que mesmo no período da licença maternidade não abandonei a formação.

... As discussões partiam sempre daquilo que vivenciava em sala de aula, dos anseios, frustrações e dúvidas que tinha no meu dia a dia de fazer docente.

... O que mais me marcou foi a reflexão sobre mim mesma como professora de matemática das séries inicias do ensino fundamental. Até onde tinha domínio dos conteúdos que me propunha a ensinar? Que importância e como era a minha relação com a matemática? Que valor eu acreditava ter a matemática para meus alunos? Que conceitos pré-estabelecidos eu tinha em relação à matemática que determinavam 
minha forma de ensinar? Eu era capaz de saber e reconhecer minhas deficiências e limitações matemáticas? (Professora HCS, relato, agosto de 2012)

A experiência do grupo também foi registrada em artigos e apresentada em espaços formais, como congressos, seminários e encontros da área, tanto pelo pesquisador quanto pelos alunos de iniciação científica e por um professor da educação básica. Os trabalhos de iniciação científica financiados pelo CNPq e as monografias de conclusão do curso também podem ser considerados como produções escritas do grupo, já que os alunos do curso de Pedagogia, responsáveis pelo desenvolvimento desses trabalhos, também integravam o GETEMAT. O depoimento escrito de um deles relata a experiência de participação no grupo:

Meu interesse em participar do GETEMAT foi ampliar meus conhecimentos, na época tinha disponibilidade de tempo para me dedicar aos estudos, queria algo mais do que uma simples graduação e confesso foi uma experiência maravilhosa e fiquei feliz com o resultado da pesquisa. Participar do projeto GETEMAT desde a sua criação foi uma oportunidade única, uma experiência de suma importância para a vida acadêmica de qualquer aluno de graduação. Minha monografia de final de curso descreveu as opiniões das professoras participantes do projeto. Observei que as professoras, mesmo diante da dificuldade em trabalhar com conteúdos de matemática, se sentiram dispostas a falar sobre isso e tirar suas dúvidas, isto é, se sentiram à vontade para questionar e aprender novas maneiras de ensinar os conteúdos de forma mais construtiva. (Aluno JP, relato, abril de 2012)

Com relação aos textos teóricos estudados pelo grupo, há duas categorias predominantes: i) textos sobre formação de professores e aprendizagem em grupos colaborativos; ii) textos que tratam de conteúdos de matemática e sobre como trabalhar matemática nos anos iniciais.

Os textos que abordam a formação de professores dos anos iniciais trabalhados com o grupo foram: Nacarato, Mengali e Passos (2009b), especialmente o primeiro capítulo, que relata as dificuldades da professora polivalente para ensinar matemática; e os dois primeiros capítulos do livro de Curi (2005), que aborda a história dos cursos de formação de professores dos anos iniciais no nosso país. Os artigos estudados que discutem a relevância dos grupos colaborativos no processo de formação do professor foram os de Fiorentini e Gimenes (2004) e Gimenes e Penteado (2008), nos quais são apresentadas as características de um grupo colaborativo e as possibilidades de desenvolvimento de propostas de formação docente nesses espaços.

Dentre os conteúdos matemáticos propriamente ditos, o conceito de número, o sistema de numeração, as operações fundamentais, a geometria e os sistemas de medidas foram estudados em Toledo e Toledo (1997), livro que tem uma abordagem piagetiana para o desenvolvimento dos conteúdos matemáticos nos anos iniciais; e no livro organizado por Panizza (2006), que trata desses conteúdos numa abordagem alinhada à chamada Didática Francesa. Também foram estudados artigos sobre a Teoria dos Campos Conceituais, de Vergnaud, especialmente os campos aditivo e multiplicativo. A resolução de problemas e as operações fundamentais foram discutidas a partir do artigo de Muniz (2009), trabalhado em 
algumas reuniões do grupo. Ainda no contexto de resolução de problemas, foram discutidas as ideias sobre cenários de investigação apresentadas por Skovsmose (2000).

Para uma discussão mais geral sobre o trabalho do professor, foi selecionado o artigo de Moura, Araújo, Moretti, Panossian e Ribeiro (2010), que apresenta o conceito de atividade, para fundamentar o trabalho do professor na organização do ensino, de acordo com os pressupostos teórico-metodológicos da psicologia histórico-cultural. Os textos sobre como trabalhar com os conteúdos matemáticos nos anos iniciais foram os seguintes: Lopes (2003), que apresenta as experiências de um grupo de professoras dos anos iniciais que desenvolveram os conteúdos matemáticos através de projetos, e o livro de Araújo (2003), que trata especificamente da estratégia de projetos; com relação ao uso de materiais manipulativos no ensino de matemática, foram discutidos os artigos de Fiorentini e Miorim (1990), Moura (2000) e Nacarato (2005).

Os registros seguintes tratam dos textos nas reuniões e apresentam indícios de como as professoras incorporavam esses estudos em suas reflexões:

Discutimos durante este encontro o texto "Eu trabalho primeiro no concreto", de Adair Mendes Nacarato. Este texto foi ao encontro das minhas interrogações da reunião anterior. Especialmente na questão de ter como verdadeiro de que os materiais usados pelos professores seriam mesmo facilitadores de aprendizagens. As colocações do autor ajudaram a me posicionar e me motivaram a tentar em sala de aula o uso do material. Claro que no meu caso, esbarro sempre nas minhas próprias limitações de compreensão dos algoritmos e do conhecimento das possibilidades do material. (Professora Anônima, Memorial, 2010)

Hoje a aula, ou melhor, o encontro foi significativo porque aprendi e revi muito sobre o cálculo mental. As leituras e apresentações expostas foram de grande valia para minha vida pessoal e profissional. Sabemos que não há receitas para trabalhar em sala, mas os questionamentos são nortes para os trabalhos futuros e atuais em sala. (Professora LOR, Memorial, 2010)

$\mathrm{O}$ quarto eixo proposto pelas autoras se refere às tarefas e atividades elaboradas $\mathrm{e}$ desenvolvidas pelo grupo. Poucas são as experiências do grupo relacionadas a esse eixo. Uma está registrada no trabalho desenvolvido pela professora $\mathrm{J}$, com a construção em conjunto do projeto "Dominó", para ser aplicado com uma turma de primeiro ano. Durante uma das reuniões no primeiro semestre de 2011, ela propôs ao grupo o planejamento de atividades para seus alunos de primeiro ano. Ela queria trabalhar com a representação numérica e o início das operações de adição e subtração, utilizando como recurso o jogo Dominó. O grupo aceitou e durante três reuniões planejaram o projeto "Dominó", sendo o resultado registrado em um software de apresentação. À medida que as atividades eram planejadas pelo grupo, a professora as desenvolvia na sala de aula e apresentava para os colegas os diferentes resultados obtidos, as dificuldades encontradas pelos alunos e também seus sucessos (Müller, 2014).

Os dados produzidos pelo GETEMAT não permitem, como já observado, que se avaliem mudanças na prática pedagógica das professoras participantes do grupo. Há relatos 
individuais sobre tentativas de experimentar novas formas de abordar o conteúdo, entretanto não houve uma produção sistemática que pudesse ser compartilhada com outros, que indicasse uma mudança mais significativa na atuação em sala de aula. Algumas reflexões apontam para estas tentativas:

Falar de como aprendemos e como ensinamos requer a conscientização de que os tempos mudaram, que a memorização não quer dizer "conhecimento" e que devemos mudar nossas estratégias em sala, principalmente porque nossos alunos necessitam do visual, do concreto, de uma aula significativa. (Professora Anônima, Memorial, 2010)

O encontro de hoje foi sobre o tema projetos. Esse tema é de muita relevância, pois muitas escolas trabalham projetos, mas não levam em conta como isso é importante de ser trabalhado no conjunto da escola. Quando um projeto é trabalhado com ênfase em abordar várias disciplinas ele tem um resultado muito importante no conhecimento dos alunos. (Professora MH, Memorial, 2010)

Foi muito importante porque aprendi muita coisa e revi, relembrei alguns temas/conteúdos que havia aprendido antes. Com certeza irei usar na sala, pois a professora deu dicas simples de como utilizar em prol dos conteúdos e ser significativo para os educandos. Enfim, foi interessante e significativa essa reunião porque irá fazer diferença para minha vida pessoal e profissional. (Professora LOR, Memorial, 2010)

No Diário de Campo produzido em 2009, há o seguinte registro que indica uma mudança de postura pedagógica de uma das professoras, que se pode inferir ter sido consequência de sua participação no GETEMAT:

Na discussão sobre os objetivos de matemática para o primeiro ano, uma professora informou que ela agora trabalha muitas situações-problema e, enquanto uns alunos desenham para resolver o problema, outros resolvem mentalmente, ou seja, cada um tinha sua própria estratégia para resolver o problema apresentado. Através dessa intervenção da professora, pode-se observar uma mudança de postura, já que no início de sua participação no grupo observou que ao trabalhar com probleminhas ia direto à aplicação do algoritmo. Agora, utiliza situações-problema e aceita diferentes formas de resolvê-las. (Diário de Campo, 19 de novembro de 2009)

O relato de uma das alunas de graduação descreve seu processo de aprendizagem no grupo:

Alguns aprendizados foram imprescindíveis para minha formação, pois através das dúvidas apresentadas pelas professoras participantes pude aprender algumas coisas que só estando na prática pedagógica aprenderia, exemplos disso são os relatos de como organizar uma aula e das dificuldades encontradas para isso. (Aluna GAS, relato, maio de 2012)

As discussões nos diversos encontros do GETEMAT procuraram sempre atender às demandas trazidas pelas integrantes do grupo, pois se entende que é a partir das necessidades do professor que a formação tem seu início, e seu fim é a busca de melhores condições de aprendizagem para os alunos. Sobre essa dinâmica, uma professora do grupo fez o seguinte relato: 
As experiências trocadas com as demais colegas participantes da formação a um só tempo eram ponto de enriquecimento e serviam como ponto de apoio para esclarecimentos de nossas dúvidas, pois as problemáticas eram quase sempre as mesmas.

Outra coisa bacana é que tivemos a oportunidade de decidir previamente que conteúdos que iríamos trabalhar sempre com antecedência. Os encontros tinham dessa forma uma pauta baseada nos conteúdos escolhidos pelos cursistas e as discussões eram complementadas com um texto que tratava sobre o tema do ponto de vista teórico. (Professora HCS, relato, agosto de 2012)

Para finalizar, destaca-se a reflexão dessa mesma docente sobre sua prática, sua participação no grupo e suas dúvidas sobre ensinar e aprender matemática:

Muitas vezes quando ensinamos matemática, não paramos para pensar como estamos ensinando. Não paramos para pensar sobre a nossa maneira de ensinar até porque essa foi a forma que aprendemos e ficam automatizadas determinadas ações e atitudes, reproduzindo conceitos e formas anos após anos. Por acreditar que aquela forma é eficaz e correta e por não saber fazer de outra forma resistimos sair da nossa zona de conforto. De fato assusta um pouco quando temos que olhar para nossa prática. Muitas vezes preferimos continuar como estamos e não nos sequer permitimos refletir.

... Vacilava entre tentar o novo ou me acovardar e permanecer como estava. Tive que tomar uma decisão corajosa. Comecei a encarar e trabalhar as minhas dificuldades para depois trabalhar com os alunos...

Posso dizer que sou outra pessoa. Tenho ainda muito a aprender certamente, mas hoje lido com a matemática de maneira harmoniosa e procuro mesmo dentro das limitações impostas pela dinâmica escolar colocar em prática o que aprendi no GETEMAT. Creio que projetos como esses, mesmo enfrentando muita resistência por parte dos docentes, pode ser o caminho para mudanças significativas na nossa educação básica. (Professora HCS, relato, agosto de 2012)

Observa-se, nessa reflexão, que a professora não apenas construiu novos caminhos e conhecimentos sobre e para sua prática como também desconstruiu conceitos sobre a forma de ensinar matemática.

Para analisar o tipo de conhecimento produzido pelo grupo, considerou-se a perspectiva teórica de Cochran-Smith e Lytle (1999), que trata das diferentes concepções de conhecimento e aprendizagem do professor.

É importante observar que nem essas autoras e nem este artigo têm intenção de classificar os tipos de conhecimento e aprendizagem do professor, colocando um tipo como superior ao outro. $\mathrm{O}$ objetivo foi registrar o tipo de conhecimento produzido pelo grupo no período em destaque.

A primeira concepção, o conhecimento para a prática, enfatiza a produção dos pesquisadores acadêmicos, que geram o conhecimento dito formal ou as teorias para uso do professor, com o objetivo de melhorar a prática. A universidade é vista como o local privilegiado de construção de saberes sobre o modo de ensinar, e Cochran-Smith e Lytle (1999, p. 261) observam que esta concepção está baseada na compreensão de que a relação 
entre conhecimento e prática pode ser pensada como "um conhecimento para melhorar a prática" docente.

As reuniões do GETEMAT, pode-se afirmar, constituíam, para as professoras da Educação Básica, o espaço de aprendizagem de um conhecimento para a prática, pois uma característica das pautas sugeridas para os encontros era majoritariamente o estudo de teorias sobre como trabalhar com os conteúdos matemáticos.

A ideia de que para ensinar é necessário um conhecimento de base que, quando dominado, permite ao professor produzir um ensino de qualidade, pode ser observada em diversos registros das professoras. Há uma preocupação, por parte delas, em "obter conhecimento" para melhorar a prática - pode-se dizer que estavam preocupadas com a obtenção de um conhecimento para o uso. Alguns relatos obtidos nos memoriais das reuniões assim revelam:

Esse encontro foi muito interessante no sentido de esclarecer dúvidas e ajudar encontrar maneiras mais simples de abordar esses conteúdos (sistemas de medida) [ênfase adicionada]. É importante lembrar que a maioria dos conhecimentos matemáticos que o educador possui é o mesmo que foi adquirido nas séries iniciais e outros de formação continuada que às vezes não atende as necessidades do professor. (Professora LU, Memorial, 2009)

Vou tentar usar o que aprendi na sala de aula porque acredito que vai facilitar para que meus alunos compreendam melhor os conteúdos. (Professora Anônima, Memorial, 2009)

Apesar de ser a segunda reunião, já percebi que este curso poderá trazer muitas informações para trabalhar com o ensino fundamental na disciplina de matemática, principalmente para mim professora do $4 .^{\circ}$ ano. Estou gostando dos debates, leituras etc. que estão sendo discutidos nos encontros. (Professora MP, Memorial, 2010)

Nesse primeiro encontro os conceitos teóricos e as propostas sugeridas pareceram interessantes. Meu objetivo com o curso é sanar algumas dificuldades em repassar o conteúdo matemático para os alunos de forma realmente significativa. (Professora $\mathrm{AD}$, Memorial, 2011)

Observa-se a tendência das professoras a pensar no grupo como um curso para obter conhecimentos sobre a matemática e sobre a forma de ensiná-la. Nos memoriais, várias professoras utilizam o termo "curso", ao invés de grupo, para se referir ao GETEMAT, e algumas se referem a "aula", ao invés de "encontro".

A segunda concepção, o conhecimento na prática, tem como ponto de partida o conhecimento na prática do professor. De acordo com as autoras, nesta segunda perspectiva, o conhecimento gerado pelos docentes competentes ou experts é crucial para produzir novos saberes sobre como ensinar. O professor é visto como um gerador de conhecimento, pois o conhecimento da profissão é construído na prática, e não por especialistas que ficam à margem do espaço da sala de aula. 
Apesar de os dados do GETEMAT oferecerem indícios de uma mobilização para a produção de um conhecimento na prática, visto que as reuniões eram pautadas nas experiências docentes, não se podem destacar produções que se caracterizem como este tipo de conhecimento. As docentes que participaram do GETEMAT tinham dificuldade em considerar sua prática como um recurso importante na geração de conhecimento. Não se viam como produtoras de um conhecimento, e sim como consumidor do que foi produzido por outros. Ao apresentarem suas dúvidas e expectativas, se limitavam ao conteúdo matemático:

É importante lembrar que a maioria dos conhecimentos matemáticos que o educador possui é o mesmo que foi adquirido nas séries iniciais e outros de formação continuada que às vezes não atende as necessidades do professor. (Professora LU, Memorial, 2010)

Quanto mais nos aprofundamos na matemática mais encantada eu fico com as várias formas existentes de explicar um mesmo assunto.... Se tivéssemos acesso a materiais concretos para a exploração, não teríamos tanta dificuldade na compreensão da matemática, quando ainda estudávamos. Percebi também que algumas colegas não compreendem esse processo de dezena e unidade, mas sentem vergonha de perguntar. (Professora Anônima, Memorial, 2009)

O encontro de hoje trouxe várias formas de trabalhar o campo multiplicativo que eu ainda não conhecia e se fiz em sala foi de forma mecânica sem possibilitar aos meus alunos a utilizar o raciocínio lógico. (Professora RO, Memorial, 2009)

A aula de hoje me fez perceber o quanto eu estava enganada com a matemática, sempre pensei que só existia uma forma de fazer a divisão. E estou trabalhando esse conteúdo com os meus alunos de $4 .^{\circ}$ ano e eles têm muita dificuldade para compreender a sua lógica da maneira que eu estava ensinando. Quem sabe agora com essas outras possibilidades que eu aprendi nessa aula de hoje. (Professora RE, Memorial, 2009)

A terceira concepção, o conhecimento da prática, parte do pressuposto de que o conhecimento que os professores precisam ter para ensinar provém de investigação sistemática do ensino, dos estudantes e do aprendizado, assim como da matéria, do currículo e da escola (Cochran-Smith \& Lytle, 1999).

De acordo com as autoras,

O conhecimento da prática é gerado pela transformação da sala de aula e das escolas em locais de pesquisa, através do trabalho colaborativo em comunidades de investigação, para compreender a co-construção do currículo, do desenvolvimento do conhecimento local, e a tomada de uma perspectiva crítica com relação a teorias e pesquisas de outros. (Cochran-Smith \& Lytle, 1999, p. 275)

O projeto GETEMAT, com a proposta para constituição do grupo de estudo, tinha o objetivo de discutir o conhecimento teórico sobre a matemática e a prática docente dos envolvidos, buscando mudanças na forma de ensinar e aprender matemática. A intenção de possibilitar a constituição de uma comunidade científica educacional, registrada no texto do projeto (Müller, 2010), traz implicitamente a ideia de formar um grupo de investigação da prática educativa, tendo como pano de fundo as aulas de matemática. No entanto, durante os 
encontros do GETEMAT, talvez por sua curta história de existência, as participantes se mostraram, muitas vezes, desestabilizadas e incomodadas com a possibilidade de apresentar sua experiência em sala de aula, para ser estudada e discutida no grupo. Assim, com exceção do projeto "Dominó" (Müller, 2014), que foi elaborado em conjunto, aplicado pela professora e discutido nos encontros, não se tem registro de outra atividade relacionada à prática em sala de aula produzida pelas professoras durante o período analisado.

Apesar dessa dificuldade do grupo em gerar um conhecimento da prática, alguns fragmentos dos memoriais apresentam as expectativas das professoras com relação ao grupo, como espaço de formação, e também demonstram a busca por práticas diferenciadas, apresentadas e discutidas:

Ao ouvir os objetivos do GETEMAT, me senti motivada a ingressar nesse estudo, acredito que temos muito a aprender, mas com o longo tempo de docência também podemos contribuir com nossos relatos de erros e acertos.... Essa iniciativa foi ótima, precisamos realmente criar o hábito de formar grupos de estudo. (Professora LUR, Memorial, 2009)

Estou encantada com as inúmeras propostas do GETEMAT. Nunca participei de encontros; neste primeiro encontro senti minha prática profissional fortalecida, pois este trabalho não traz receitas de como ensinar, mas orienta o trabalho em sala de aula. Acredito que seja prematuro dizer que o projeto todo será interessante, mas a julgar por este encontro o andamento só vem a somar. Durante a reunião estivemos motivadas e curiosas, além de compreendermos um pouco mais sobre teorias de utilização de jogos. (Professora JAS, Memorial, 2011)

O professor tem que desconstruir crenças ou filosofias pessoais para que possa repassar aos alunos que estudar matemática não é um bicho de sete cabeças, mas um processo que com atividades diversificadas, divertidas, desafiadoras podemos aprender, sem decorar e o melhor: não esquecer com o tempo. (Professora Anônima, Memorial, 2009)

Refletir sobre a prática pedagógica, ser instruído a prosseguir e oferecer algo melhor para os alunos superarem os desafios, foi o que mais me chamou atenção neste encontro. Sugiro que a metodologia continue. (Professora EL, Memorial 2010)

Em suma, no caso do GETEMAT não foi possível desenvolver um conhecimento próprio do grupo baseado nas investigações de sala de aula. O que se observa, na maioria dos memoriais e relatos, são reflexões que demonstram a aprendizagem da prática docente pelas professoras.

\section{Para concluir}

Ao revisitar os dados produzidos pelo grupo GETEMAT, buscou-se revisitar o movimento de constituição do grupo, procurando-se caracterizá-lo como uma comunidade de aprendizagem e identificar o conhecimento produzido por seus integrantes no período destacado. 
Os dados foram analisados, considerando-se as características-chave das comunidades de aprendizagem do professor apontadas por Cochran-Smith e Lytle (1993, 2002), e pode-se afirmar que o grupo GETEMAT se tornou, ao longo de sua existência, um espaço de formação continuada dos professores dos anos iniciais do município de Vilhena (RO) para o ensino de matemática e constituiu-se, por sua proposta, em uma comunidade de aprendizagem do professor. No período estudado, apesar de os registros apontarem para reflexões baseadas na prática docente, o conhecimento e a aprendizagem construídos pelo grupo podem ser caracterizados como conhecimento e aprendizagem para a prática, e não gerados pela investigação da prática propriamente dita. As professoras buscavam o conhecimento para melhorar seu trabalho em sala de aula, e os registros indicam uma reflexão sobre sua prática a partir das discussões do grupo, indicando desejo de mudanças.

Para concluir, destaca-se que as lentes teóricas proporcionadas pelos trabalhos de Cochran-Smith e Lytle $(1993,1999,2009)$ possibilitaram um olhar mais apurado sobre o que foi produzido por esse grupo ao longo de sua trajetória. No entanto, é importante observar que os pontos analisados marcam um caminho próprio percorrido pelo grupo, considerandose a diversidade histórica e cultural da cidade, da universidade e dos espaços escolares em que o GETEMAT estava inserido, e não se esgotaram as possibilidades de estudo da experiência.

\section{Referências}

Araújo, U. F. (2003). Temas transversais e a estratégia de projetos. São Paulo: Moderna.

Campos, W. R., \& Müller, M. C. (2009). A utilização de jogos no ensino da matemática nos anos iniciais do ensino fundamental. In: Anais do II Seminário de Educação: interculturalidade, políticas públicas e educação escolar. Rolim de Moura (RO): Departamento de Educação.

Carvalho, D. L., \& Conti, K. (Org.). (2009). Histórias de colaboração e investigação na prática pedagógica em matemática. Campinas: Alínea.

Carvalho, D. L., \& Pamplona, A. S. (2009). Comunidades de prática e conflitos de identidade na formação do professor de matemática que ensina estatística. In: D. Fiorentini, R. C. Grando, \& R. G. S. Miskulin (Orgs.). Práticas de formação e de pesquisa de professores que ensinam matemática (pp. 211-231). Campinas: Mercado de Letras.

Cochran-Smith, M., \& Lytle, S. L. (1993). Inside/Outside: teacher research and knowledge. New York: Teachers College Press.

Cochran-Smith, M., \& Lytle, S. L. (1999). Relationship of knowledge and practice: Teacher learning in the communities. Review of Research in Education, 24, 249-305.

Cochran-Smith, M., \& Lytle, S. L. (2002). Teacher Learning Communities. In J. Guthrie (Ed.). Encyclopedia of Education (2nd ed.). New York: Macmillan.

Cochran-Smith, M., \& Lytle, S. L. (2009). Inquiry as stance: practitioner research for next generation (pp. 118-166). New York: Teacher College Press.

Curi, E. (2005). A matemática e os professores dos anos iniciais. São Paulo: Musa.

Zetetiké, Campinas, SP, v.26, n.2, mai./ago., 2018, p.299-317

ISSN 2176-1744 
Fiorentini, D. (2013). A investigação em Educação Matemática desde a perspectiva acadêmica e profissional: desafios e possibilidades de aproximação. Cuadernos de Investigación y Formación en Educación Matemática, 8(11), 61-82.

Fiorentini, D., \& Cristovão, E. M. (2007). Histórias e investigações delem aulas de matemática. Campinas: Alínea.

Fiorentini, D., \& Espinosa, A. J. (Orgs.) (2003). Histórias de aulas de matemática: compartilhando saberes profissionais. Campinas: Gráfica FE: CEMPEM - Faculdade de Educação - Unicamp.

Fiorentini, D., \& Miorim, M. A. (1990). Uma reflexão sobre o uso de materiais concretos e jogos no ensino da matemática. Boletim SBEM-SP. 4(7), 5-10.

Fiorentini, D., \& Nacarato, A. M. (Org.). (2010). Cultura, formação e desenvolvimento profissional de professores que ensinam matemática. São Paulo: Musa.

Gimenes, J., \& Penteado, M. G. (2008). Aprender Matemática em grupo de estudos: uma experiência com professoras de séries iniciais. Zetetiké, 16(29), 73-92. Disponível em: https://periodicos.sbu.unicamp.br/ojs/index.php/zetetike/article/view/8647036/13937.

Guthrie, J. (Eds.). (2002). Encyclopedia of Education (2nd ed.). New York: Macmillan.

Lopes, C. A. E. (Org.). (2003). Matemática em projetos: uma possibilidade. Campinas: FE/UNICAMP.

Moura, M. O. (2000). A séria busca no jogo: do lúdico na Matemática. In T. M. Kishimoto, (Org.). Jogo, brinquedo, brincadeira e a educação (pp.73-87). São Paulo: Cortez.

Moura, M. O., Araújo, E. S., Moretti, V. D., Panossian, M. L., \& Ribeiro, F. D. (2010). Atividade Orientadora de Ensino: unidade entre ensino e aprendizagem. Rev. Diálogo Educ., 10(29), 205-229. Disponível em: https://periodicos.pucpr.br/index.php/dialogoeducacional/article/download/3094/3022.

Müller, M. C. (2010). Grupo de estudo e trabalho pedagógico de ensino de matemática: formação continuada de professores dos anos iniciais para o ensino de Matemática. In Anais do $17^{\circ}$ COLE. Campinas, SP: ALB. Retirado em 31 de outubro, 2012, de http://alb.org.br/arquivomorto/edicoes_anteriores/anais17/txtcompletos/sem20/COLE_1954.pdf

Müller, M. C. (2011). Formação continuada de docentes dos anos iniciais: a proposta do GETEMAT. In Anais XIII Conferência Interamericana de Educação Matemática. Recife, PE: EDUMATEC-UFPE. Retirado em 30 de outubro, 2012, de http://www.cimm.ucr.ac.cr/ocs/index.php/xiii_ciaem/xiii_ciaem/paper/view/374.

Müller, M. C. (2014). GETEMAT - uma experiência de formação de professores dos anos iniciais em uma comunidade de aprendizagem. In: M. A. Gonçalves Júnior, E. M. Cristovão, \& R. C. R. Lima (Orgs.). Grupos colaborativos e de aprendizagem do professor que ensina matemática: repensar a formação de professores é preciso! (pp. 40-49). Campinas, SP: FE/UNICAMP. Retirado em 10 de agosto, 2017, de https://issuu.com/marcosantoniogoncalvesjr/docs/i_simp_gcapemat_140710_web_jul10 
Muniz, C. A. (2009). Diversidade dos conceitos das operações e suas implicações nas resoluções de classes de situações. In: G. Guimarães, \& R. Borba (Org.). Reflexões sobre o ensino de matemática nos anos iniciais de escolarização (pp. 101-108). Recife: SBEM.

Nacarato, A. M. (2005). Eu trabalho primeiro no concreto. Revista de Educação Matemática, 9(9-10), 1-6.

Nacarato, A. M., Mengali, B. L. S., \& Passos, C. L. B. (2009a). A formação matemática da professora polivalente: desafios de ensinar o que nem sempre aprendeu. In: Nacarato, A. M., Mengali, B. L. S., \& Passos, C. L. B. A matemática nos anos iniciais do ensino fundamental: tecendo fios do ensinar e do aprender (pp. 15-38). Belo Horizonte: Autêntica.

Nacarato, A. M., Mengali, B. L. S., \& Passos, C. L. B. (2009b). A matemática nos anos iniciais do ensino fundamental: tecendo fios do ensinar e do aprender. Belo Horizonte: Autêntica.

Panizza, M. (2006). Ensinar Matemática na Educação Infantil e nas séries iniciais: análise e propostas. Porto Alegre: Artmed.

Pimenta, S. G. (2005). Pesquisa-ação crítico-colaborativa: construindo seu significado a partir de experiências com a formação docente. Educação e Pesquisa, 31(3), 521-539.

Skovsmose, O. (2000). Cenários para investigação. Bolema - Boletim de Educação Matemática, 13(14), 66-91.

Toledo, M., \& Toledo, M. (1997). Didática de Matemática: como dois e dois. São Paulo: FTD. 